\title{
A Prospective Analysis of Near-Death Experiences in Cardiac Arrest Patients
}

\author{
Janet Schwaninger, R.N., B.S.N. \\ Paul R. Eisenberg, M.D., M.P.H. \\ Barnes-Jewish Hospital, Washington University \\ School of Medicine \\ Kenneth B. Schechtman, Ph.D. \\ Alan N. Weiss, M.D., F.A.C.C. \\ Washington University School of Medicine
}

\begin{abstract}
The objective of this study was to assess prospectively the frequency of near-death experiences (NDEs) in patients suffering a cardiac arrest, to characterize these experiences, and to assess their impact on psychosocial and spiritual attitudes. We prospectively evaluated all patients who suffered a cardiac arrest at Barnes-Jewish Hospital from April 1991 through February 1994, excluding those in the surgical intensive care unit, using a scale designed to specify criteria for NDEs, a recorded interview regarding the experience, an experience rating form, and a follow-up questionnaire regarding psychosocial attitudinal life changes. Of the 174 patients who suffered a cardiac arrest, 55 patients survived, of whom 30 patients were interviewable. Of those 30 patients interviewed, seven ( 23 percent) had a NDE, and four others ( 13 percent) reported an NDE during a prior life-threatening illness. The experiences were most frequently characterized by ineffability, peacefulness, painlessness, lack of fear, detachment from the body, and no sense of time or space. Significant differences were noted in the follow-up psychosocial assessment between patients
\end{abstract}

Janet Schwaninger, R.N., B.S.N., is Cardiovascular Coordinator at Barnes-Jewish Hospital at the Washington University School of Medicine in St. Louis, MO. At the time of this study, Paul R. Eisenberg, M.D., M.P.H., was Medical Director of the Cardiac Intensive Care Unit at Barnes-Jewish Hospital and Professor of Medicine at Washington University School of Medicine; currently he is Medical Director, Cardiovascular Therapeutic Area, at the Lilly Corporate Center in Indianapolis, IN. Kenneth B. Schechtman, Ph.D., is Associate Professor of Biostatistics at Washington University School of Medicine, where Alan N. Weiss, M.D., is Professor of Medicine, Cardiovascular Division. Reprint requests should be addressed to Ms. Schwaninger at Barnes-Jewish Hospital, South Campus, Washington University Cardiology Consultants, Suite 16419, \#1 Barnes-Jewish Hospital Plaza, St. Louis, MO 63110; e-mail: jschwani@im.wustl.edu. 
who experienced an NDE and those who did not with regard to personal understanding of life and self, attitudes toward others, and changes in social customs and religious/spiritual beliefs. Of importance, patients reported it was beneficial to receive psychosocial support before hospital discharge after having an NDE. The results suggest that NDEs are fairly common in cardiac arrest survivors. The experiences consisted of a number of core characteristics and changed psychological, social, and spiritual awareness over both the short and long term.

KEY WORDS: prospective study; cardiac arrest survivors; near-death experiences; life changes; psychosocial support.

The near-death experience (NDE) is a subjective event with transcendental or mystical components that many people experience on the threshold of death. The five main stages of the experience are (1) a feeling of peace, calm, painlessness, and lack of fear; (2) a sense of detachment from the physical body or sensation of floating out of the body, in which experiencers may find themselves looking down on their physical body and surroundings and perceive themselves as dying or being dead; (3) encountering some form of darkness and passing through a dark tunnel; (4) ascending toward a light at the end of the darkness; and (5) entering the light or entering into a world or state in which the light appears to have its origin (Ring, 1980). Other components often associated with the experience include ineffability of the experience; a life review in the form of vivid and nearly instantaneous visual images; an encounter with a presence, which may be seen, sensed, inferred, or intuited; an encounter with deceased loved ones and/or spiritual or religious figures; and reaching a boundary (the "threshold effect") or participating in the decision to return to this existence and to the body (Ring, 1980). The number of stages or components, their order of occurrence, and the quality of experience vary from individual to individual.

Accounts and awareness of NDEs date to antiquity. In 1975, Raymond Moody introduced the term "near-death experience" and characterized the NDE based on a retrospective analysis of experiencers' accounts. The NDE is a complex subjective experience with certain common components that can occur in association with a wide range of lifethreatening situations, including cardiac arrest. The significance of these experiences remains widely disputed, as does their potential impact on the health and well-being of patients. Previous retrospective studies have shown that NDEs occur independent of age, sex, education, and cultural or religious backgrounds (Moody, 1975; Ring, 1980). 
The findings of these studies suggest that NDEs may result in changes in attitudes, values, and spiritual beliefs (Corcoran, 1988; Greyson, 1983a; Greyson and Stevenson, 1980; Morse and Perry, 1992; Noyes, 1980; Ring, 1980).

The objective of this study was to characterize prospectively these experiences and their frequency in patients surviving cardiac arrest and to assess the impact of NDEs on psychosocial and spiritual attitudes. We conducted a prospective study to reduce sampling bias, and characterized NDEs at least 24 hours after the event but before hospital discharge by use of a structured interview, experience analysis form, and Bruce Greyson's NDE Scale (Greyson, 1983b). We also administered a follow-up questionnaire to the entire sample 6 months after the interview, and compared the results of those patients who had NDEs (NDErs) with those of patients who suffered a cardiac arrest without an NDE (nonNDErs).

\section{Methods}

\section{Selection of Participants}

From April, 1991, through February, 1994, all patients who experienced a cardiac arrest in Barnes-Jewish Hospital excluding those in the surgical intensive care unit were identified and evaluated for inclusion in the study. Surgical intensive care patients were excluded due to difficulty with tracking the occurrence of cardiac arrest in that unit. Cardiac arrest was defined as the absence of a cardiac rhythm that could sustain circulation, that is, ventricular fibrillation or cardiac standstill, with no discernable blood pressure or respirations. Patients were excluded from the study if they suffered from a drug overdose, emotional instability with a prior psychiatric diagnosis, or medical instability that rendered them unable to answer questions.

\section{Procedure}

Patients who suffered a cardiac arrest were approached no sooner than 24 hours after the arrest, to allow confusion or lethargy to resolve and to permit stabilization of their medical problems, but before their discharge from the hospital. The average time period was 2 to 3 days following the cardiac arrest. Patients were interviewed by a member of the study team to determine their eligibility; all patients who were eligible 
based on the inclusion criteria consented to participate in the protocol, which was approved by the Human Studies Committee (Institutional Review Board) of Washington University Medical Center.

Those patients who reported no subjective experience during their cardiac arrest were included in the study but did not undergo the complete interview. Those who recalled any subjective experience, including those with an NDE before the index cardiac arrest, were asked all of the interview questions. In order to avoid influencing responses, we allowed the patients to report their experience subjectively before starting the structured interview. The interview was tape recorded or taken in written form, at the patient's request. The average interview lasted 30 minutes, and could be extended at the patient's request.

All patients evaluated in the hospital were contacted 6 months after the initial interview and sent a follow-up questionnaire.

\section{Instruments}

The interview protocol was based on Kenneth Ring's interview schedule consisting of 14 multi-part questions regarding the experience and five questions regarding religious beliefs and practices before and after the experience (Ring, 1980, pages 265-270). The interview rating form was used to analyze the experience (Ring, 1980, pages 275279). Greyson's NDE Scale (Greyson, 1983b) was used to determine which patients satisfied empirical criteria for having had an NDE. At the request of the Washington University Medical Center Human Studies Committee, to avoid influencing patients' responses the NDE scale was not administered directly but rather was completed by study personnel based on each patient's recorded interview. NDE Scale items are categorized into cognitive, affective, paranormal, and transcendental components, with each component comprised of four items. Each item has three possible responses: a strongly positive response given 2 points, a moderately positive response given 1 point, and a negative response given no points. Patients with a total score less than 7 points were defined as not meeting criteria for an NDE.

The follow-up form consisted of Ring's 42-item Life Changes Questionnaire (Ring, 1984, pages 276-278); five questions asking about telepathic ability, the experience of seeming to know what others will say before they say it, awareness of dreams, sense of intuitiveness, and out-of-body experiences; nine additional questions addressing possible 
physical changes after near-death experiences; and one question asking whether patients felt they had benefited from being allowed to verbalize their experience.

\section{Statistical Analysis}

The follow-up questionnaire items were measured on a 5-point Likert scale, with answers scored as strongly increased, increased, unchanged, decreased, and strongly decreased, so that lower values were associated with greater increases. Because ordered categorical variables were analyzed, we used nonparametric methods. Wilcoxon's 2-sample rank sum test was used to compare ranked variables, and $\chi^{2}$ or Fisher's exact test for dichotomous variables. Because a large number of statistical tests were performed, it is possible that some analyses have achieved significance by chance. All data were analyzed by use of the SAS computer program.

\section{Results}

\section{Sample Demographics}

During the study period, 174 patients suffered a cardiac arrest, of whom 119 (68 percent) died. Of the 55 surviving patients, 25 were not interviewed: 20 patients ( 12 percent) had suffered neurologic damage, 3 ( 2 percent) had neurologic damage prior to the arrest, and 5 ( 3 percent) remained intubated through discharge. The remaining $30 \mathrm{pa}-$ tients ( 17 percent) were interviewable and constituted our study sample (see Fig. 1).

Of the 30 patients in the study sample, 15 (50 percent) were male and 15 (50 percent) female. Twenty-nine patients ( 97 percent) were Caucasian and one (3 percent) African-American. The age range was 23 to 86 years, with a mean of 60 years. Eighteen patients ( 60 percent) described their religious preference as Protestant, 3 (10 percent) as Catholic, 1 ( 3 percent) as Jewish, and 8 ( 27 percent) described no preference. Twenty-two patients ( 73 percent) were married, 3 (10 percent) widowed, 2 ( 7 percent) single, 2 ( 7 percent) divorced, and 1 (3 percent) separated. Six patients (20 percent) had attended college, 19 (63 percent) had graduated from high school but not gone to college, 2 ( 7 percent) had not gone to high school, and 3 (10 percent) did not describe their educational level. 


\section{Figure 1}

Study Population Derived from all Codes Called in

Barnes-Jewish Hospital from April 1991 to February 1994, Excluding the Surgical Intensive Care Unit.

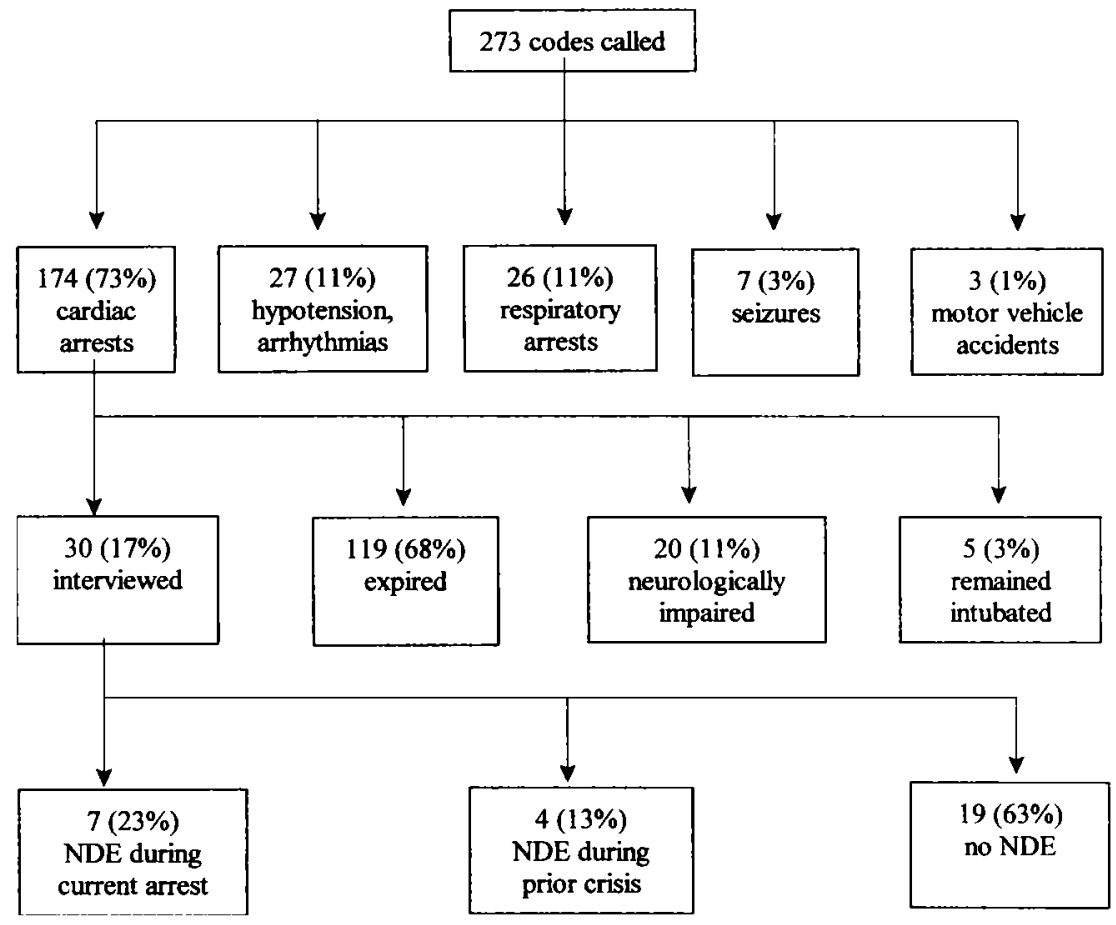

Near-Death Experiencers and Nonexperiencers

Of the 30 interviewable survivors of cardiac arrest, 7 (23 percent) described experiences classified as NDEs by scoring 7 or more points on the NDE Scale. Four additional patients (13 percent) did not have an NDE during the index cardiac arrest, but had had one in association with a prior life-threatening event. For purposes of comparison, these 11 patients comprised the group of near-death experiencers (NDErs), and the remaining 19 patients who had never had an NDE comprised the group of nonNDErs. Of the 19 nonNDErs, 16 had no recollection of their cardiac arrest, and 3 had some recollection but no NDE. Sociodemographic variables of NDErs and nonNDErs are shown in Table I; there were no significant differences between the two groups on these variables. The occupations of the NDErs included four homemakers, 


\section{Table I}

Sample Demographics

\begin{tabular}{lcc}
\hline & NDErs $(N=11)$ & nonNDErs $(N=19)$ \\
\hline Gender & $4(36 \%)$ male & $11(58 \%)$ male \\
Race & $7(64 \%)$ female & $8(42 \%)$ female \\
Age & $10(91 \%)$ Caucasian & $19(100 \%)$ Caucasian \\
Religion & $1(9 \%)$ African-American & \\
& 23 to 84 years & 29 to 86 years \\
& (mean = 53) & (mean = 64) \\
& $9(82 \%)$ Protestant & $9(47 \%)$ Protestant \\
Marital status & & $3(16 \%)$ Catholic \\
& $2(18 \%)$ none & $1(5 \%)$ Jewish \\
& $7(64 \%)$ married & $6(32 \%)$ none \\
& $1(9 \%)$ widowed & $15(79 \%)$ married \\
& $1(9 \%)$ single & $2(11 \%)$ widowed \\
& $1(9 \%)$ divorced & $1(5 \%)$ single \\
& $1(9 \%)$ separated & $1(5 \%)$ divorced \\
Education & $2(18 \%)$ attended college & $4(21 \%)$ attended college \\
& $8(73 \%)$ graduated & $11(58 \%)$ graduated \\
& high school & high school \\
& $1(9 \%)$ less than & $1(5 \%)$ less than \\
& high school & high school \\
& & $3(16 \%)$ unknown
\end{tabular}

a cook, an electrical engineer, a receptionist, a schoolteacher, a housekeeper, an administrator, and a retiree.

\section{NDE Scale Responses}

Table II presents positive responses (responses scoring either 1 or 2 points) to the 16 items on the NDE Scale among the 11 patients who reported NDEs. Transcendental and affective component items received the highest number of positive responses, whereas cognitive component items received the fewest. Those items receiving the highest number of positive responses were a feeling of peace ( 100 percent of NDErs), an out-of-body experience ( 90 percent), seeing deceased spirits or religious figures ( 72 percent), and encountering a brilliant light and a mystical being or presence ( 63 percent each). Only one of these NDErs reported a life review, and none reported apparent extrasensory perception. 
Table II

Number of NDErs $(N=11)$ Giving Positive

Responses to NDE Scale Items

$\begin{array}{lc}\text { Cognitive Component } & \\ \text { Time distortion } & 1(9 \%) \\ \text { Thought acceleration } & 1(9 \%) \\ \text { Life review } & 1(9 \%) \\ \text { Sudden understanding } & 2(18 \%) \\ \text { Affective Component } & 11(100 \%) \\ \text { Peace } & 2(18 \%) \\ \text { Joy } & 5(45 \%) \\ \text { Cosmic unity } & 7(63 \%) \\ \text { Brilliant light } & \\ \text { Paranormal Component } & 6(54 \%) \\ \text { Sensory vividness } & 0(0 \%) \\ \text { Extrasensory perception } & 1(9 \%) \\ \text { Precognitive visions } & 10(90 \%) \\ \text { Out-of-body experience } & \\ \text { Transcendental Component } & 6(54 \%) \\ \text { Otherworldly experience } & 7(63 \%) \\ \text { Mystical presence } & 8(72 \%) \\ \text { Deceased spirits/religious figures } & 5(45 \%) \\ \text { Border/point of no return } & \end{array}$

\section{Phenomenological Descriptions of NDEs}

Those patients who reported an NDE with the index cardiac arrest tended to focus on the specific phenomenological features of the experience and on its significant emotional impact. Those patients who reported an NDE associated with a life-threatening event in the past reported their experiences with the same clarity of detail as if it had also just occurred. Although they had had time to assimilate and integrate the experience into their cultural and religious framework, they had only a slight reduction in emotional response upon discussing their experience.

Patients' narrative accounts of their NDEs were analyzed with Ring's (1980) rating form. All 11 NDErs (100 percent) described ineffability of the experience. Five patients ( 45 percent) reported a subjective sense of dying, and five ( 45 percent) reported a subjective sense of being dead. In terms of feelings or sensations during the NDE, all 11 (100 percent) reported peacefulness, 10 (90 percent) reported calmness, 10 (90 percent) 
reported painlessness, 10 (90 percent) reported no fear, 7 ( 63 percent) reported relaxation, 6 (54 percent) reported pleasantness, 6 (54 percent) reported happiness, 5 (45 percent) reported quiet, 4 (36 percent) reported serenity, 4 ( 36 percent) reported lightness, 2 ( 18 percent) reported warmth, 2 (18 percent) reported joy or exaltation, 1 (9 percent) reported relief, and 1 (9 percent) reported thoughts speeded up. None of the NDErs reported resignation, curiosity, anxiety, fear, anger, dread, despair, or anguish. Two patients (18 percent) described unusual noises during the NDE.

In terms of the sense of movement during the NDE, 5 patients $(45$ percent) reported floating, 3 ( 27 percent) reported moving without the body, 1 (9 percent) reported walking, and 1 (9 percent) reported dreamlike movement. None of the NDErs reported running, flying, or echoic movements. Five NDErs (45 percent) reported feeling peaceful on moving; none reported feeling exhilarated, fearful, panicky, or struggling.

In regard to features sensed, 4 NDErs (36 percent) described a tunnel, 3 ( 27 percent) described gates, 3 ( 27 percent) described human figures, 2 (18 percent) described other beings, 2 (18 percent) described a dark void, 2 (18 percent) described an illuminated scene, 2 (18 percent) described music, and 1 each ( 9 percent) described a city, a long archway, a mansion, a golden palace, a stairway, clouds, and vivid colors. None of the NDErs described a path or road, garden, valley, meadow, or fields.

In regard to a sense of bodily separation, 10 NDErs (90 percent) reported feeling detached from the body but did not see it, whereas 2 (18 percent) reported being able to view their bodies. Nine NDErs (82 percent) reported no sense of time and 1 (9 percent) reported that time speeded up; none reported a sense of timelessness or a normal sense of time. Nine ( 82 percent) reported no sense of space and 1 ( 9 percent) reported a sense of infinite space with no boundaries; none reported a normal sense of space. Ten (90 percent) reported no sense of their body, 2 ( 18 percent) reported feeling light, 2 ( 18 percent) reported a sense of weightlessness, and none reported ordinary bodily weight. No NDErs reported a sense of loneliness.

In regard to the presence of others, 6 NDErs (54 percent) described God or a higher power, 4 (36 percent) described angels, 4 (36 percent) described a guide or voice, 3 (27 percent) described deceased relatives, and 1 ( 9 percent) described ambivalent entities. None described living persons or deceased friends.

Seven NDErs (63 percent) reported light or illumination, while none reported colors or that the light hurt their eyes. One (9 percent) reported visualizing scenes from the future, and one ( 9 percent) reported 
scenes from her past. Five ( 45 percent) reported reaching a border, the "threshold effect."

In regard to feelings upon recovery from the NDE, 9 respondents (82 percent) described a sense that the experience was "real," 7 NDErs (63 percent) described happiness, 3 (27 percent) described disappointment, 2 (18 percent) described resentment, 2 (18 percent) described peace, 1 (9 percent) described anger, 1 ( 9 percent) described relief, and 1 (9 percent) described joy. No NDErs described shock, pain, or gladness, and none thought the question about feelings upon recovery was irrelevant.

In regard to their concept of death, all 11 (100 percent) mentioned survival of the soul after death of the body, 10 (90 percent) mentioned continuance of life at another level, 7 (63 percent) mentioned peace, 6 (54 percent) mentioned a beautiful experience, 1 (9 percent) mentioned bliss, 1 ( 9 percent) mentioned a journey, and 1 ( 9 percent) mentioned reincarnation. None of the NDErs mentioned annihilation, nothingness, a transitional state, merging with universal consciousness, or having no concept of death.

Ten NDErs (90 percent) reported increased appreciation of life after the NDE, 9 ( 82 percent) reported a renewed sense of purpose, 8 (72 percent) reported feeling more caring or loving; and none reported feeling vulnerable, fearful, curious, or more interested. Ten NDErs (90 percent) reported stronger religious beliefs, whereas none reported weaker religious beliefs. Ten (90 percent) reported decreased fear of death, 7 (63 percent) reported no fear of death, and none reported increased fear of death. Three ( 27 percent) reported that the NDE helped them recover quicker and 1 (9 percent) reported that it helped save his life.

\section{Follow-Up Questionnaire}

Eight of the 11 NDErs in this study (73 percent) returned completed follow-up questionnaires mailed 6 months after the initial interview; two NDErs had died in the interim and one could not be located. Ten of the 19 nonNDErs (53 percent) returned completed follow-up questionnaires; two non NDErs had died in the interim.

Ring's Life Changes Questionnaire. Mean scores of NDErs and nonNDErs on the 42 items of Ring's Life Changes Questionnaire are presented in Table III. As noted above, responses on this Likert-type questionnaire ranged from " $1=$ strongly increased" to " $5=$ strongly decreased," with " 3 " indicating "no change." Those items that showed 


\section{Table III}

Mean Scores of NDErs $(N=8)$ and nonNDErs $(N=10)$ on Follow-Up Questionnaire

\begin{tabular}{|c|c|c|c|c|}
\hline Item & NDErs & nonNDErs & $T^{a}$ & $p$ \\
\hline 1. Desire to help others & $1.50 \pm 0.76$ & $2.50 \pm 0.85$ & 52.5 & .027 \\
\hline 2. Compassion for others & $1.62 \pm 0.91$ & $2.20 \pm 0.92$ & 62.5 & .211 \\
\hline $\begin{array}{l}\text { 3. Appreciation for } \\
\text { ordinary things }\end{array}$ & $1.37 \pm 0.52$ & $2.00 \pm 0.82$ & 58.5 & .102 \\
\hline $\begin{array}{l}\text { 4. Ability to listen } \\
\text { to others }\end{array}$ & $1.50 \pm 0.53$ & $2.40 \pm 0.70$ & 50.0 & .015 \\
\hline 5. Feelings of self worth & $1.62 \pm 0.92$ & $3.00 \pm 0.53$ & 44.5 & .009 \\
\hline $\begin{array}{l}\text { 6. Interest in psychic } \\
\text { phenomena }\end{array}$ & $2.12 \pm 0.83$ & $2.63 \pm 0.74$ & 56.5 & .197 \\
\hline $\begin{array}{l}\text { 7. Concern with material } \\
\text { things }\end{array}$ & $2.87 \pm 1.13$ & $3.00 \pm 1.05$ & 75.0 & .963 \\
\hline 8. Tolerance for others & $1.75 \pm 1.03$ & $2.67 \pm 0.50$ & 49.5 & .026 \\
\hline $\begin{array}{l}\text { 9. Interest in making } \\
\text { a good impression }\end{array}$ & $2.37 \pm 0.92$ & $2.90 \pm 1.10$ & 66.5 & .378 \\
\hline $\begin{array}{l}\text { 10. Concern with spiritual } \\
\text { matters }\end{array}$ & $1.62 \pm 0.74$ & $2.50 \pm 0.71$ & 52.5 & .030 \\
\hline $\begin{array}{l}\text { 11. Interest in organized } \\
\text { religion }\end{array}$ & $1.62 \pm 0.92$ & $3.10 \pm 1.10$ & 48.5 & .012 \\
\hline $\begin{array}{l}\text { 12. Understanding } \\
\text { of myself }\end{array}$ & $1.87 \pm 0.83$ & $2.56 \pm 0.53$ & 55.0 & .087 \\
\hline $\begin{array}{l}\text { 13. Desire to achieve higher } \\
\text { consciousness }\end{array}$ & $1.87 \pm 0.83$ & $2.78 \pm 0.44$ & 50.0 & .023 \\
\hline $\begin{array}{l}\text { 14. Ability to express } \\
\text { love for others }\end{array}$ & $1.37 \pm 0.52$ & $2.50 \pm 0.71$ & 46.0 & .006 \\
\hline $\begin{array}{l}\text { 15. Interest in living the } \\
\text { good life }\end{array}$ & $1.87 \pm 0.99$ & $3.00 \pm 0.47$ & 51.5 & .015 \\
\hline $\begin{array}{l}\text { 16. Insight into problems } \\
\text { of others }\end{array}$ & $1.62 \pm 0.92$ & $2.60 \pm 0.52$ & 52.0 & .025 \\
\hline 17. Appreciation of nature & $1.50 \pm 0.53$ & $2.40 \pm 0.70$ & 50.0 & .015 \\
\hline 18. Religious feelings & $1.62 \pm 0.92$ & $2.70 \pm 0.48$ & 50.5 & .016 \\
\hline $\begin{array}{l}\text { 19. Understanding of what } \\
\text { life is about }\end{array}$ & $1.75 \pm 0.71$ & $2.80 \pm 0.42$ & 46.0 & .004 \\
\hline 20. Sense of purpose in life & $1.50 \pm 0.56$ & $2.80 \pm 0.42$ & 44.0 & .002 \\
\hline 21. Belief in higher power & $1.62 \pm 0.92$ & $2.70 \pm 0.67$ & 52.0 & .019 \\
\hline 22. Understanding of others & $1.50 \pm 0.53$ & $2.67 \pm 0.71$ & 44.0 & .005 \\
\hline 23. Sense of sacredness of life & $1.37 \pm 0.52$ & $2.78 \pm 0.44$ & $\begin{array}{r}39.0 \\
\quad(C o\end{array}$ & $\begin{array}{c}<.001 \\
\text { atinued }\end{array}$ \\
\hline
\end{tabular}




\section{Table III}

\section{(Continued)}

\begin{tabular}{|c|c|c|c|c|}
\hline Item & NDErs & nonNDErs & $T^{\alpha}$ & $p$ \\
\hline $\begin{array}{l}\text { 24. Ambition for higher } \\
\text { living standard }\end{array}$ & $1.87 \pm 0.99$ & $3.20 \pm 0.63$ & 49.5 & .006 \\
\hline 25. Desire for solitude & $2.25 \pm 0.89$ & $3.00 \pm 0.47$ & 57.0 & .049 \\
\hline $\begin{array}{l}\text { 26. Sense of inner meaning } \\
\text { of life }\end{array}$ & $1.25 \pm 0.46$ & $2.60 \pm 0.70$ & 43.0 & .002 \\
\hline $\begin{array}{l}\text { 27. Involvement in } \\
\text { family life }\end{array}$ & $1.50 \pm 0.76$ & $2.30 \pm 0.82$ & 55.5 & .059 \\
\hline 28. Fear of death & $3.00 \pm 1.31$ & $3.20 \pm 0.63$ & 72.5 & .761 \\
\hline $\begin{array}{l}\text { 29. Desire to become } \\
\text { well known }\end{array}$ & $2.50 \pm 0.93$ & $3.20 \pm 0.63$ & 63.0 & .087 \\
\hline 30. Tendency to pray & $1.37 \pm 0.52$ & $2.60 \pm 0.70$ & 44.5 & .003 \\
\hline $\begin{array}{l}\text { 31. Openness to the notion } \\
\text { of reincarnation }\end{array}$ & $2.29 \pm 0.95$ & $3.20 \pm 1.03$ & 49.0 & .138 \\
\hline $\begin{array}{l}\text { 32. Interest in self } \\
\text { understanding }\end{array}$ & $1.75 \pm 0.71$ & $2.60 \pm 0.52$ & 51.0 & .018 \\
\hline $\begin{array}{l}\text { 33. Inner sense of God's } \\
\text { presence }\end{array}$ & $1.25 \pm 0.46$ & $2.70 \pm 0.48$ & 39.0 & $<.001$ \\
\hline $\begin{array}{l}\text { 34. Feelings of personal } \\
\text { vulnerability }\end{array}$ & $2.00 \pm 0.93$ & $2.50 \pm 0.71$ & 63.5 & .246 \\
\hline $\begin{array}{l}\text { 35. Belief that there is } \\
\text { life after death }\end{array}$ & $1.50 \pm 0.76$ & $2.80 \pm 1.03$ & 48.5 & .011 \\
\hline $\begin{array}{l}\text { 36. Interest in what } \\
\text { others think of me }\end{array}$ & $2.25 \pm 1.04$ & $3.10 \pm 0.99$ & 60.0 & .098 \\
\hline $\begin{array}{l}\text { 37. Concern with political } \\
\text { matters }\end{array}$ & $2.12 \pm 0.83$ & $3.20 \pm 0.79$ & 51.0 & .016 \\
\hline $\begin{array}{l}\text { 38. Desire for material } \\
\text { success }\end{array}$ & $2.87 \pm 1.36$ & $3.30 \pm 0.67$ & 74.0 & .885 \\
\hline 39. Acceptance of others & $1.87 \pm 0.83$ & $2.60 \pm 0.70$ & 56.5 & .066 \\
\hline $\begin{array}{l}\text { 40. Search for personal } \\
\text { meaning }\end{array}$ & $2.25 \pm 1.16$ & $2.89 \pm 0.33$ & 60.5 & .214 \\
\hline $\begin{array}{l}\text { 41. Concern with social } \\
\text { justice }\end{array}$ & $2.12 \pm 0.83$ & $2.89 \pm 0.33$ & 52.5 & .031 \\
\hline $\begin{array}{l}\text { 42. Interest in death } \\
\text { and dying issues }\end{array}$ & $2.12 \pm 0.83$ & $2.50 \pm 0.53$ & 66.0 & .353 \\
\hline
\end{tabular}

${ }^{a} T=$ smaller of observed sum of ranks, Wilcoxon 2 -sample rank sum test. 
statistically significant differences between the NDErs and nonNDErs could be grouped into four categories, reflecting (1) changes in spiritual, religious, and/or global attitudes, (2) personal understanding of life and self, (3) attitudes toward others, and (4) changes in social customs.

In regard to spiritual, religious, and/or global attitudes, NDErs reported significantly greater increases than did nonNDErs in an inner sense of God's presence, sense of sacredness of life, tendency to pray, interest in organized religion, belief in life after death, religious feelings, appreciation of nature, belief in a higher power, desire to achieve higher consciousness, and concern with spiritual matters. In regard to personal understanding of life and self, NDErs reported significantly greater increases than did nonNDErs in a sense of inner meaning in life, sense of purpose in life, understanding of what life is about, feeling of self worth, interest in self understanding, and desire for solitude.

In regard to attitudes toward others, NDErs reported significantly greater increases than did nonNDErs in understanding of others, ability to express love for others, ability to listen to others, tolerance for others, insight into problems of others, and desire to help others. In regard to social customs, NDErs reported significant greater increases than did nonNDErs in ambition for a higher living standard, interest in living the good life, concern with political matters, and concern with social justice.

Intuitive and Paranormal Experiences. Patients were asked if they noted any changes since their cardiac arrest in their telepathic ability (defined in the question), the experience of seeming to know what somebody will say before he or she says it, awareness of dreams, and sense of intuitiveness, or if they had ever had an out-of-body experience. As shown in Table IV, a significantly higher proportion of NDErs than of nonNDErs reported increased intuitiveness and out-of-body experiences. More NDErs than nonNDErs reported increases in telepathic ability, knowing what someone else will say, and awareness of dreams, but those differences were not statistically significant.

Physical Changes. As shown in Table V, NDErs and nonNDErs did not differ significantly in their responses to the nine questions addressing perceived physical changes since their cardiac arrest, with the single exception that half the NDErs but none of the nonNDErs reported a sense of a surrounding energy force or shield. The majority of both groups reported changes in their circadian cycles following their cardiac arrest. In response to an open-ended question about physical changes not explored, those NDErs who had contact with a brilliant light often 


\section{Table IV}

Positive Responses of NDErs $(N=8)$ and nonNDErs $(N=10)$ to Questions About Intuitive or Paranormal Experiences

\begin{tabular}{llccc}
\hline \multicolumn{1}{c}{ Item } & NDErs & nonNDErs & $\chi^{2}$ & $p$ \\
\hline Increased telepathic ability & $3(38 \%)$ & $1(10 \%)$ & 1.94 & .163 \\
Increased knowing what someone & $4(50 \%)$ & $1(10 \%)$ & 3.54 & .060 \\
$\quad$ will say & & & & \\
Increased awareness of dreams & $4(50 \%)$ & $1(10 \%)$ & 3.54 & .060 \\
Increased intuitiveness & $4(50 \%)$ & $0(0 \%)$ & $a$ & .023 \\
Out-of-body experience & $5(63 \%)$ & $1(10 \%)$ & 5.83 & .016 \\
\hline
\end{tabular}

${ }^{a}$ Fisher's exact test used rather than $\chi^{2}$.

reported that there had been a direct transmission of the light's energy into them, and that it remained with them after the experience. Other physical changes reported by NDErs included an increase in mental awareness, mood swings, increased sensitivity to cold, tingling sensations in the spine when thinking or saying something negative, and development of a "special touch."

\section{Table V}

Positive Responses of NDErs $(N=8)$ and nonNDErs $(N=10)$ to Questions About Physical Changes

\begin{tabular}{lllll}
\hline \multicolumn{1}{c}{ Item } & NDErs & nonNDErs & $\chi^{2}$ & $p$ \\
\hline Changes in brightness to the eyes & $5(63 \%)$ & $3(30 \%)$ & 1.90 & .168 \\
Changes in skin sensitivity & $4(50 \%)$ & $4(40 \%)$ & 0.18 & .671 \\
Changes in circadian cycles & $5(63 \%)$ & $6(60 \%)$ & 0.01 & .914 \\
Changes in allergic reactions & $2(25 \%)$ & $3(30 \%)$ & 0.05 & .814 \\
$\begin{array}{l}\text { Changes in sensitivities } \\
\quad \text { to drugs/medicine }\end{array}$ & $0(0 \%)$ & $1(10 \%)$ & $a$ & 1.00 \\
$\begin{array}{l}\text { Changes in sensations of } \\
\quad \text { taste/touch/texture }\end{array}$ & $1(13 \%)$ & $1(10 \%)$ & 0.03 & .867 \\
$\begin{array}{l}\text { Sense of a surrounding energy } \\
\quad \text { force/shield }\end{array}$ & $4(50 \%)$ & $0(0 \%)$ & $a$ & .023 \\
$\begin{array}{l}\text { Looking or feeling younger } \\
\text { Any changes in the hands }\end{array}$ & $2(25 \%)$ & $0(0 \%)$ & $a$ & .183 \\
\hline
\end{tabular}

${ }^{a}$ Fisher's exact test used rather than $\chi^{2}$. 
Benefit From Study. All 8 NDErs who returned the follow-up form reported that it had been very beneficial to discuss their experiences before they left the hospital.

\section{Discussion}

Alternative and complementary medical therapies are attracting greater interest and are gaining increasing acceptance (Astin, 1998; Eisenberg, Davis, Ettner, Appel, Wilkey, Van Rompay, and Kessler, 1998). In addition, medical personnel are becoming more interested in the psychological and spiritual aspects of medical care, including NDEs.

Findings of previous retrospective studies suggest an association between NDEs and subsequent psychospiritual changes (Greyson, 1983a; Morse and Perry, 1992; Noyes, 1980; Ring, 1980, 1984). The results of this prospective study confirm these findings. Statistically significant differences were observed between NDErs and nonNDErs in regard to changes in attitudes toward personal understanding of life and self, attitudes toward others, and changes in social customs and religious beliefs. There were also perceived physical changes and reports of subsequent intuitive and telepathic abilities.

Two instruments were used to analyze the interview data: the NDE scale and the experience analysis form. The NDE Scale showed NDEs to be categorized predominantly by transcendental, affective, and paranormal components. The experience analysis evaluation showed that these experiences had an ineffable quality and were associated most often with enhanced peacefulness, calmness, painlessness, and lack of fear. There was often a feeling of detachment from the physical body and patients frequently reported no sense of time or space.

After resuscitation, most of the NDErs reported the feeling that the experience was "real." They felt their experiences could not be explained in physiological or psychological terms. Several felt resentful or frustrated at having to return or at being revived, although others described a feeling of happiness. Individuals often interpreted the experience according to their cultural and religious beliefs. Immediately after the experience all of the NDErs felt that when the body dies the "soul/spirit/essence" survives, and most felt that life continues at another level. Experiencers often came to view themselves as integral parts of the universe with an awareness of eternal life. They reported an increased appreciation for life and a renewed sense of purpose in life. NDErs reported stronger religious beliefs, a decrease in the fear of 
death, and an increase in feelings of loving and caring. Several of the patients experienced the "threshold effect" and offered as reasons for their return to this existence the pull of loved ones and/or a sense of one's life purpose needing to be fulfilled.

In a retrospective study, Michael Sabom and Sarah Kreutziger (1977) found that 11 of 50 hospital patients ( 22 percent) who had had a nearfatal crisis with unconsciousness reported an NDE of some kind. Thomas Locke and Franklin Shontz (1983) found NDEs reported by 7 of 32 college students ( 22 percent) who had been near death. In this prospective study, NDEs occurred in 7 of 30 patients (23 percent) who survived an index cardiac arrest. Although each individual's experience was unique, they all contained features recognized to be characteristic of NDEs. Whether some features are more significant than others or whether each individual weighs the features uniquely is not well understood. For example, contact with a brilliant light is frequently associated with significant psychosocial or spiritual change (Morse and Perry, 1992). The patients in this study who saw the light described it as white, golden, brilliant, and a beautiful white mist, which did not hurt their eyes. Almost all of the patients who had contact with the light felt the light's energy remained with them and reported having a sense of a physical force or energy shield surrounding them after the NDE.

Although it is possible that cardiac arrest survivors who do not report NDEs simply may not remember them, it seems unlikely that NDEs accompany every near-death situation. Of note, a patient who has an NDE with one cardiovascular arrest will not necessarily have an NDE with a subsequent arrest, although this has been reported: indeed one of the seven patients in this study who had an NDE with the index arrest had also had one previously. However, at least one investigator has observed that those having one NDE were less likely to report a second associated with another life-threatening event (Ring, 1980). Of interest, the NDEr in this study who had also had a previous experience reported encountering the same spiritual entity on both occasions.

One patient in this study reported meeting in her NDE a deceased brother whom she had not previously known. The existence of this sibling was subsequently verified by her parents. All the NDErs in this study who encountered a spiritual voice reported the voice as masculine. Several patients reported the development of intuitive and telepathic abilities as a result of their experiences.

Although this study did not specifically address the relationship between the occurrence of an NDE and time to recovery, three of the 
NDErs expressed the belief that the experience definitely helped them to recover more quickly. This area warrants further investigation. One NDEr in this study was totally convinced that the experience helped save his life. This raises the question of whether NDEs at the point of death have some survival value. Russell Noyes and Roy Kletti (1976) and Greyson (1983c, 2001) have suggested this idea independently.

One of the limits of this research and prospective studies of this type is the small number of patients who survive a cardiac arrest to report a NDE. Another limitation is the impossibility of personality testing before and after the NDE to record changes objectively.

However, the findings indicate that a powerful spiritual experience does change awareness of spirituality and well-being both over the short and long term. It has the ability to change attitudes about life and death and to affect quality of life. Spiritual experiences thus can have significant impact on health care, potentially affecting recovery and long-term health. As suggested by Glenn Roberts and John Owen (1988), these patients can provide an important model of how therapeutic change can be observed after a brief experience. This example provides an impetus to continue the search for methods to improve patients' mental outlook. For example, the beneficial effects of prayer (Harris, Gowda, Kolb, Strychacz, Vacek, Jones, Forker, O'Keefe, and McCallister, 1999) and meditation on physical health and treatment outcome are now being examined.

Allowing patients to discuss and validate their experiences, express their emotions, and ask questions appears to be therapeutic. Brian Bates and Adrian Stanley (1985) have stressed the importance of how interactions with healthcare professionals affect the subsequent psychological life of the patient. Hospital personnel should be educated to facilitate and encourage discussion of NDEs, to provide education and psychosocial support, and to help individuals adapt and grow from their experience (Clark, 1984; Corcoran, 1988; Greyson, 1983c; Serdahely, Drenk, and Serdahely, 1988). Accepting that NDEs present is an important part of the management of patients who survive a cardiac arrest.

In summary, patients with near-death experiences have a heightened spiritual awareness and experience significant changes in their attitudes toward understanding of life and self, attitudes toward others, and changes in social customs and religious beliefs. Patients also felt it was significantly beneficial to be able to express their experience and to receive psychosocial support prior to hospital discharge. 


\section{References}

Astin, J. A. (1998). Why patients use alternative medicine: Results of a national study. Journal of the American Medical Association, 279, 1548-1553.

Bates, B. C., and Stanley, B. A. (1985). The epidemiology and differential diagnosis of near-death experience. American Journal of Orthopsychiatry, 55, 542-549.

Clark, K. G. (1984). Clinical intervention with near-death experiences. In B. Greyson and C. P. Flynn (Eds.), The near-death experience: Problems, prospects, perspectives (pp. 242-255). Springfield, IL: Charles C Thomas.

Corcoran, D. K. (1988). Helping patients who've had near-death experiences. Nursing 88 , $153,607-617$.

Eisenberg, D. M., Davis, R. B., Ettner, S. L., Appel, S., Wilkey, S. Van Rompay, M., and Kessler, R. C. (1998). Trends in alternative medicine use in the United States, 19901997: Results of a follow-up national survey. Journal of the American Medical Association, 280, 1569-1575.

Greyson, B. (1983a). Near death experiences and personal values. American Journal of Psychiatry, 140, 618-620.

Greyson, B. (1983b). The near-death experience scale: Construction, reliability, and validity. Journal of Nervous and Mental Disease, 171, 369-375.

Greyson, B. (1983c). The psychodynamies of near-death experiences. Journal of Nervous and Mental Disease, 171, 376-381.

Greyson, B. (2001). Posttraumatic stress symptoms following near-death experiences. American Journal of Orthopsychiatry, 71, 368-373.

Greyson, B., and Stevenson, I. (1980). The phenomenology of near-death experiences. American Journal of Psychiatry, 137, 1193-1196.

Harris, W. S., Gowda, M., Kolb, J. W., Strychacz, C. P., Vacek, J. L., Jones, P. G., Forker, A., O'Keefe, J. H., and McCallister, B. D. (1999). A randomized, controlled trial of the effects of remote, intercessory prayer on outcomes in patients admitted to the coronary care unit. Archives of Internal Medicine, 159, 2273-2278.

Locke, T. P., and Shontz, F. C. (1983). Personality correlates of the near-death experience: A preliminary study. Journal of the American Society for Psychical Research, 77, 311318.

Moody, R. A. (1975). Life after life. Covington, GA: Mockingbird Books.

Morse, M., and Perry, P. (1992). Transformed by the light: The powerful effect of near-death experiences on people's lives. New York, NY: Villard.

Noyes, R. (1980). Attitude change following near-death experiences. Psychiatry, 43, 234242.

Noyes, R., and Kletti, R. (1976). Depersonalization in the face of life-threatening danger: An interpretation. Omega, 7, 103-114.

Ring, K. (1980). Life at death: A scientific investigation of the near-death experience. New York, NY: Coward, McCann, and Geoghegan.

Ring, K. (1984). Heading toward omega: In search of the meaning of the near-death experience. New York, NY: William Morrow.

Roberts, G., and Owen, J. (1988). The near-death experience. British Journal of Psychiatry, 153, 607-617.

Sabom, M. B., and Kreutziger, S. (1977). The experience of near death. Death Education, $1,195-203$.

Serdahely, W. J., Drenk, A., and Serdahely, J. J. (1988). What carers need to understand about the near-death experience. Geriatric Nursing, 9, 238-241. 